\title{
Analysis of Supply Quality of General Aviation Industry Policy in China
}

\author{
Zhang Liang, Hu Chengwei* \\ Guangzhou Civil Aviation College, Guangzhou, 510000 \\ *corresponding author: 25267764@QQ.com
}

Keywords: Analysis, Supply quality, Aviation, Policy

\begin{abstract}
The paper first analyzes the evolution path of China's general aviation industry policy, analyzes the general aviation industry policies in China, and summarizes the main six types of policies at the current stage. The effect of the implementation of general aviation industry policies is positive. Less than two aspects are analyzed in order to provide a basis for future industrial policy formulation.
\end{abstract}

\section{The evolution path of China's general aviation industry policy}

The general aviation industry in China has undergone different stages of development. The characteristics of the policies in each stage are highly consistent with the features of China's economic system at that time, showing an evolutionary trend of gradual progress and classification. Thanks to the gradual improvement of China's economic system, China's general aviation industry policy will gradually be expanded and improved. A series of industrial development planning policies have been promulgated and implemented. The key areas of industrial development have been deepened and expanded to ensure the general direction of China's general aviation industry and the continuity of policies. The evolution path of China's general aviation industry policy has undergone a preliminary evolution from the transition period of the system to the market economy system; from the initial perfection of the socialist market economic system to the overall advancement of structural reform evolution.

(1) Establish a preliminary evolution from the period of institutional transition to a market economy (1978-2001)

From 1978 to 1991, it was a period before the establishment of the socialist market economic system from the reform and opening up. At this stage, the general aviation industry in China is from the stagnation of the Cultural Revolution period to the stage of full recovery. China's general aviation industry has begun to try new applications on the basis of its original traditional business. At the national level, the government began to gradually use the fiscal and monetary policies to regulate the general aviation industry. However, due to the lack of market economy control experience, the general aviation industry is still dominated by direct regulation. As far as civil aviation authorities and other industry authorities are concerned, the characteristics of general aviation industry policies during this period are characterized by the main features of administrative and planning measures as the main features of general aviation industry development, and industrial policies are dominated by direct planning interventions. In order to guide specific businesses, due to lack of experience, policy adjustments are too frequent, lack of necessary continuity and stability, and the quality of policy regulation is severely low.

From 1992 to 2001, it was a period when the socialist market economic system was initially established. At this stage, the Chinese general aviation industry has embarked on a systematic development path around two aspects of "improving the general aviation development environment and enhancing general aviation operations service capabilities". At the national level, the government began to focus on using economic and legal indirect means to manage general aviation industry production and business activities, focusing on the coordinated use of different policies, and paying attention to maintaining the stability and continuity of policies, but due to the lack of policies. The application experience of adaptability and flexibility has made the general aviation 
industry's ability to cope with external environmental impacts low; As far as civil aviation bureaus and other industry authorities are concerned, in order to continue to further optimize the policies and regulations that are used to guide GA's specific businesses, a general aviation industry policy has emerged.

(2) From the initial perfection of the socialist market economic system to the overall advancement of structural reforms (2002-present)

From 2002 to 2015, it was the initial stage of perfecting the socialist market economic system. At this stage, the State Council and the Central Military Commission promulgated the opportunity to implement the "Opinions on Deepening the Management Reform of China's Low-altitude Airspace." China's general aviation industry has focused on improving the development environment of general aviation and the scale of development and quality of development has taken a new stage. At the national level, the government has actively adopted fiscal policies and prudent monetary policies to accelerate the strategic restructuring of the general aviation industry and effectively enhanced the coordination, sustainability, and endogenous power of the development of the general aviation industry; As far as the civil aviation authority and other industry authorities are concerned, the general aviation industry policy has mainly started from industrial guidelines and management methods, special industrial development planning, industrial development guidance, industrial restructuring measures, industrial control measures, and special funds for industrial development. Form a systematic industrial policy system.

The year 2016 is the first year for China to successfully establish a well-off society and the beginning of the structural reform in the "Thirteenth Five-Year Plan" period. This stage is the key stage for China's general aviation industry to grow from quantity to quality. By taking advantage of the opportunity for civil aviation to change from a big country to a powerful one, general aviation industry will gradually shorten the gap with developed countries such as the United States, making general aviation a new engine for promoting national economic development. At the national level, the government will actively promote a proactive and steady planning policy that promotes the development of the general aviation industry from the top level macro perspective, so as to comprehensively solve the current unbalanced and inadequate status of general aviation industry development; For civil aviation bureaus and other industry authorities, it is bound to strengthen the general theoretical research on general aviation industry policies, strengthen supervision from the three perspectives of policy formulation, policy implementation, and policy outcomes to ensure the general and scientific nature of general aviation industry policies. Really become a guarantee to promote the development of the general aviation industry.

\section{China General Aviation Industry Policy Supply Category}

Industrial policy as one of the important means to promote the healthy, sustained and efficient development of the industry is a potential efficiency capital. A sound and efficient industrial policy has a significant role in promoting the development of the industry. It can produce a kind of efficiency, coordinate the various resource elements required for industrial development, and form a joint force to promote industrial development; otherwise, it will become a barrier to industrial development. Through the analysis of China's general aviation industry policy, we can see that general aviation industry policies mainly include special plans for industrial development, industrial development guidance, special funds for industrial development and financial support measures, industry access and regulatory measures, scientific research support, and management measures, Industrial Technology Standards and Management Measures Category 6 policies.

(1) Special plans for industrial development

The so-called development quality of the general aviation industry is the development capability embodied in or reflected in the development of the general aviation industry, including the industry's own sustainable development, key elements of the support for the development of the navigation industry and the domestic and international market competitiveness of the navigation industry. With the development of China's economy, special plans for industrial development have become an important means to guarantee the quality of industrial development. How to conduct 
general aviation industry layout, optimize the development structure of the general aviation industry, form an orderly general aviation production chain, etc., and need to guide the policy. Therefore, the first type of supply for China's general aviation industry policy is the special plan for industrial development. The industrial development special planning policy shall include the guiding ideology of industrial development, industrial development principles, industrial development goals, and industrial development measures from the macro perspective.

(2) Industrial Development Guidance

General aviation, as China's "strategic emerging industry system," will play an important role in promoting regional economic restructuring, expanding domestic demand, and protecting people's livelihood. How to optimize the specific aspects of industrial development and guide the specific direction of industrial development requires policy guidance. Therefore, the second supply type of China's general aviation industry policy is the guidance to promote the development of the general aviation industry. The guidance for industrial development has detailed planning from the guiding ideology, basic principles, and development goals for industrial development.

(3) Special funds for industrial development and financial support measures

Due to the late start of China's general aviation industry development, unbalanced regional development of industries and unequal levels of industrial public services, the development of investment and financing systems is imperfect and the aircraft design, manufacture, purchase, operation and maintenance costs and airport construction and operation are too high. The characteristics of the large amount of investment, long return time, and large positive externalities represent a huge financial pressure for the development of China's general aviation industry. Therefore, the third type of supply of China's general aviation industry policy is to support various types of financial and financial policies such as special funds, financial subsidies, and financial support measures established for industrial development. Special funds for industrial development and financial support measures have created conditions and development momentum for the expansion and endogenous development of the general aviation industry.

(4) Industry Access and Supervision Measures

According to incomplete statistics, by the end of 2017, the number of general aviation enterprises in China has reached a scale of more than 300, and the number of general aviation aircraft has reached more than 2,000 vehicles. This shows that more and more countries and private capital have entered the general aviation industry. However, China's general aviation industry's industry access and regulatory measures are still relatively lacking of systemic and scientific nature, and are embodied in three aspects: First, the functions of the general aviation market access management agency in China are vague; second, China's general aviation market investment. The main body is single and lacks sound investment. Third, lack of unified supervision measures, these factors make China's general aviation market, from the industry access or industry supervision and general aviation market, a good development prospects do not match. Therefore, the fourth supply type of China's general aviation industry policy supply is industry access and supervision measures. Industry access and supervision measures have played a positive role in further stimulating market vitality, reducing the access threshold for navigation companies and improving the quality of industry operation supervision.

(5) Research support and management measures

The general aviation industry is a high-tech industry. Independent innovation and strengthening the ability to research and develop new technologies is the driving force and source of industrial development. However, due to the fact that China's general aviation industry is relatively young, immature and unsystematic, it has caused a serious shortage of industrial innovation capabilities and has limited the development of the industry. Therefore, the fourth type of supply provided by China's general aviation industry policy is the research support and management measures to promote industrial technological innovation. Scientific research support and management measures have important practical significance for further creating an independent innovation environment for the entire industry, promoting general aviation industry science and technology innovation, transforming achievements, and increasing the degree of integration of science and technology with 
industry.

(6) Industrial technical standards and management methods

Compared with European and American aviation industry developed countries, China's general aviation industry is still in the catch-up phase, the lack of empirical research on industrial technology standards and management methods, resulting in industrial technology standards and management methods of scientific, forward-looking, competitive lags far behind Europe and the United States The strong aviation industry has made the general aviation industry less prosperous. Therefore, the sixth supply type of China's general aviation industry policy supply is the industrial technology standard and management method that can achieve the technical standardization and scientific management of general aviation industry development. Industrial technology standards and management methods have important practical significance for promoting the development of China's general aviation industry and competing for international competition.

\section{Evaluation of the Implementation of China's General Aviation Industry Policy}

(1) Positive evaluation of the implementation effect of China's general aviation industry policy 1) A major breakthrough in the development of general aviation industry

For a long time, national policies have continued to tilt to support public transport flights, causing the development of general aviation transportation to lag behind that of public transport. Through the general aviation industry development policies and guidance issued in recent years, especially after 2010, a series of general aviation industry policies were promulgated, which strengthened the application of general aviation industry policies. The objects of policy adjustments are centered on general aircraft manufacturing and general aircraft. Operations, general aviation infrastructure construction, etc., cover almost all areas of general aviation applications, covering the entire industry chain of the first, second and third, and the content of the general aviation industry development policy has also been more detailed, and the number of policies has increased significantly. The measures were also more specific, and the direct intervention and support for the development of the general aviation industry was significantly strengthened, which promoted the rapid development of the general aviation industry.

2) Significant achievements have been made in the adjustment of the internal structure of the general aviation industry

Through the adjustment of policies, the internal industrial structure of the general aviation industry is more rationalized. The research and development, production, and manufacturing of general aviation aircraft involved in the aviation industry; general aircraft operation and management; general aviation infrastructure investment and construction, general aviation talents training, and other fields in coordination with each other; strong industrial structure conversion capability and good The adaptability can adapt to changes in market demand and bring about the best benefits; through the adjustment of policies, the general aviation industry structure is more advanced, and the general aviation industry has changed from simple imitation manufacturing to new materials, electronics, communications, energy, The emergence and development of a series of related high-tech technologies with independent intellectual property rights, such as precision manufacturing, have enabled the general aviation industry structure system to transform from a lower level to a higher level.

3) Form a batch of general aviation companies with industry leadership and demonstration role

Under the support and guidance of general aviation industry policies in recent years, China has formed a number of general aviation enterprises with strong financial strength, rich operating experience, and strong resource control. These enterprises have operated steadily in their original businesses, increased their competitiveness through scale and intensification, and ensured operating efficiency. At the same time, it will expand and expand on the basis of its core business, actively explore new general aviation markets, and seek new profit growth points for the general aviation industry. These companies can play a more active role in allocating resources in the general aviation market, playing an important leading role and radiation effects.

(2) Evaluation of the implementation effect of China's general aviation industry policy 
First, the problem of the internal structure adjustment of the general aviation industry has not been fundamentally changed. First of all, problems such as the weak foundation of the industry, irrational structure, and weak development impetus, and unbalanced, unmatched, and uncoordinated development restrict the economic and social benefits of general aviation. It is difficult to meet the needs of multi-level, diversified, and personalized social services; Second, general aviation companies lack of independent innovation, industrial upgrading lacks core technology and talent support. The key structural adjustments in the core basic components, advanced basic technologies, basic software, and industrial technology bases are progressing slowly. Third, the general aviation industry is unevenly distributed and regional development is uneven. The general aviation industry is too concentrated in the economically developed regions. The development of the navigable industry is lopsidedly pursuing high speeds and high output values, blindly investing in projects, stalls, repeated investment, low technological content, and a small proportion of added value, resulting in waste of resources.

Second, some general aviation industry policies have poor operability in the process of formulation and implementation, and the degree of implementation of policies is not high, which has brought some negative impacts on the overall development of the industry and has caused some controversies. In 2017, the Civil Aviation Administration of China conducted operation subsidies and license subsidies for 136 general aviation companies, with a total subsidy of RMB 3200.6 million. The largest beneficiary in the Great Northern Wilderness received a maximum of $37,768,800$ Yuan in subsidies, while the minimum was only 10,200 Yuan, because it was a policy to subsidize general aviation operations and pilot training according to business volume. It is that the reinforcement does not make up for weaknesses and the traditional business does not make up for new business. In spite of the large amount of subsidies, most companies are still unable to achieve regular profitability, and most of the profits are mainly dependent on subsidies. Most industries have not yet formed a clear and stable profit model. According to the industry dynamics of the past few years, most of the people who enter navigation are entering the mentality of testing the water and occupying the site because of the existence of subsidies. This is also the lack of standardization of policy formulation, and even has a negative impact on the development of the industry.

Third, industrial policies have also exposed some problems in the process of formulation and implementation. For example, the quality of policy makers needs to be improved, and the pros and cons of policy formulation ability are closely related to the quality of policy makers. The policy makers are often subject to their own subjective understanding of the problem. Each policy maker has different methods and means for collecting information, and the information is not the same, which directly affects their understanding, understanding and design of policy formulation. . The general aviation industry policies promulgated under this scenario are quite a part of policies that are inefficient or even out of order; the compulsory administrative direct intervention policy has been further strengthened, and the intervention in the micro-economy has become more extensive, meticulous, and direct, thus reflecting strong Directly intervene in the market, restrict market competition, replace the regulatory features of the market mechanism with government choices, and have a strong planned economy; the legal basis for policy formulation is lacking, and China's general aviation industry policy formulation process still lacks uniform legal norms, resulting in The repeatability and repetitiveness of the formulation of the navigable industry policy will not only reduce the performance of the policy, but also make it difficult for enterprises and the public to trust the policy; the effective participation of general aviation companies in the policy formulation process is not high. The degree of conformity between the navigable industrial policy and the development of the industry is not high, and it cannot achieve the goal of truly serving the enterprise and guiding the development of the industry.

\section{References}

[1] History of China's General Aviation Development. Department of Civil Aviation.2010.12

[2] Outline of China's General Aviation "Thirteenth Five-Year Plan" Development Plan 
[3] Qiming Gao. A Comparative Study of General Aviation Industry Development in China and the United States [J]. Journal of Xi'an Aeronautical University, 2013, 31(2):33-35. 